\title{
Performansi EoIP-PPTP dengan EOIP-L2TP pada Router Mikrotik
}

\section{EoIP-PPTP Performance by EOIP-L2TP on Microtik Router}

\author{
Zabellnur $^{1}$, Bongga Arifwidodo ${ }^{2, *}$ \\ ${ }^{12}$ Program Studi S1 Teknik Telekomunikasi \\ Fakultas Teknik Telekomunikasi dan Elektro, Institut Teknologi Telkom Purwokerto \\ Jl. D.I. Panjaitan No.128 Purwokerto, Jawa Tengah, Indonesia \\ 2,* Penulis Korespondensi: ${ }^{2}$ bongga@ittelkom-pwt.ac.id \\ ${ }^{1} 14101118 @$ ittelkom-pwt.ac.id
}

Received on 06-11-19, accepted on 31-01-20, published on 31-01-20

Abstrak

Router berfungsi melewatkan paket Internet Protocol (IP) dari suatu jaringan yang berbeda, dengan metode pengalamatan serta protokol tertentu agar bisa melewatkan suatu paket data. Suatu topologi jaringan untuk mengirimkan sebuah data digunakan berbagai protocol seperti PPTP (Point to Point Tunneling Protocol), L2TP (Layer 2 Tunneling Protocol), dan EoIP (Ethernet over Internet Protocol). Dimana Protokol ini digunakan sebagai keamanan data yang akan di kirim maupun diterima. Metode tunneling adalah suatu teknologi yang ditugaskan untuk menangani hingga menyediakan koneksi point to point dari sumber tujuannya. Tunnel ini menggunakan EolP Tunnel antara PPTP maupun L2TP dalam jaringan untuk memproses pengiriman data, maka dari itu penelitian ini akan membandingkan kinerja PPTP dengan L2TP pada router mikrotik. Pada penelitian ini dilakukan uji coba untuk mengetahui seberapa baik layanan file sharing dengan jaringan PPTP dan L2TP dengan Tunnel EolP, kemudian dianalisa parameter QoS. Pengujian menggunakan 3 skenario pada layanan file sharing sebesar 5MB, 10MB, dan 15MB. Hasil layanan file sharing PPTP dan L2TP yang termasuk kategori sangat bagus menurut standarisasi TIPHON adalah L2TP. Untuk nilai packet loss yang digunakan pada layanan file sharing L2TP lebih baik dari PPTP. Terlihat nilai packet loss yang didapat pada variasi 15 Mbps sekitar 0 - 1\% dibandingkan PPTP dengan packet loss sekitar $17 \%$.

Kata kunci: EoIP, L2TP, PPTP, Tunneling

\section{Abstract}

Routers function to pass Internet Protocol (IP) packets from a different network, with specific addressing methods and protocols in order to pass a data packet. A network topology to transmit data uses various protocols such as PPTP (Point to Point Tunneling Protocol), L2TP (Layer 2 Tunneling Protocol), and EolP (Ethernet over Internet Protocol). This protocol is used as data security to be sent or received. The tunneling method is a technology assigned to provide point-to-point connections from the source to the destination. This tunnel uses the EoIP Tunnel between PPTP and L2TP in the network to process data transmission; therefore, this study will compare the performance of PPTP with L2TP on a Mikrotik router. In this study, a trial was conducted to determine how good file-sharing services are with PPTP and L2TP networks with EoIP tunnels then analyzed the QoS parameters. The test uses three scenarios on file-sharing services of 5, 10, and $15 \mathrm{MB}$. The results of PPTP and L2TP file-sharing services, categorized as very good according to the TIPHON standard, are L2TP. The packet loss value used in L2TP file-sharing services is better than PPTP. It can be seen that the packet loss value obtained at the 15 Mbps variation is around $0-1 \%$ compared to PPTP with a packet loss of around $17 \%$.

Keywords: EoIP, L2TP, PPTP, Tunneling 


\section{INTRODUCTION}

Pengguna jaringan internet di kalangan organisasi yang memiliki kantor pusat dan cabang, yang mana memiliki infrastruktur server dan client, banyak yang memanfaatkan internet sebagai penghubung untuk komunikasi data. Internet menjadi media komunikasi serta pertukaran data yang terpusat, dimana server menyimpan data kemudian dapat diakses oleh client. Salah satu cara untuk menikmati koneksi internet yang aman digunakan sebuah teknologi yaitu koneksi privat yang aman. Virtual Private Network (VPN) merupakan salah satu teknologi yang dimplementasikan sebagai solusi atas kebutuhan untuk menghubungkan kantor pusat dan kantor cabang. Cara kerja jaringan VPN seolah-olah menjadi sebuah jaringan privat dengan membuat sebuah "terowongan" (tunnel) tanpa membuat jalur khusus secara fisik, sehingga komunikasi antar kantor dan organisasi dapat dilakukan secara aman sehingga memungkinkan membentuk kantor pusat dan kantor cabang menjadi satu broadcast domain atau satu network yang sama walaupun terpisah oleh jaringan publik, sehingga komunikasi diantaranya bersifat privat. Protokol yang digunakan untuk membentuk sebuah "terowongan" (tunneling protocol) ini bermacam-macam, diantaranya : Point to Point Tunneling Protocol (PPTP), L2TP (Layer 2 Tunnel Protocol)[1]. Pada penelitian ini dibutuhkan yang namanya bridge sebagai alat jaringan untuk menggabungkan dua sambungan data dengan pengulangan paket antar dua jaringan lokal, dimana nanti interface yang berbeda menjadi satu didalam segmen network yang sama. Memanfaatkan tunnel EoIP yang di bridge dengan interface lokal antara dua router sehingga menjadi satu interface[2].

Berdasarkan latar belakang tersebut, penulis mengambil topik Perbandingan Performansi EOIP-PPTP dengan EOIP-L2TP. Penelitian yang dilakukan sebelumnya menguji layanan VPN dengan diberi beban trafik dan sistem keamanan. Oleh karena itu, pada penelitian ini memperbandingkan performansi kinerja protokol PPTP dengan L2TP dalam layanan file sharing. Adapun layanan yang digunakan untuk menguji kualitas jaringan tersebut menggunakan layanan sharing data dengan variasi pada data yang dikirimkan

\section{LITERATURE REVIEW}

Penelitian Herman Kuswanto melakukan implementasi jaringan VPN menggunakan protokol EoIP. Perancangan jaringan VPN dilakukan dengan konfigurasi EoIP tunnel pada kedua router untuk jalur penghubung antar kantor cabang. Berdasarkan implementasi yang dilakukan ada beberapa tahapan yang diuji dalam perancangan jaringan tersebut, dengan mengkonfigurasi di masing-masing router beserta alamat IP dan tahapan pengujian selanjutnya dilakukanlah tes ping dari Router 1 ke PC Client dan selanjutnya tes ping Router 2 ke PC Client. Dengan digunakannya protokol EoIP Tunel, kantor yang mempunyai koneksi internet dan mendapatkan bandwidth internet tersebut, dapat juga memanfatkan jaringan publik/internet tersebut sebagai jalur jembatan penghubung privasi/internet antar dua atau lebih kantor cabang, sehingga antara kantor cabang tersebut terhubung dalam suatu satu segmen yang sama di jaringan internet, walaupun dalam aspek keamanan EoIP tidak memperbolehkan enkripsi seperti VPN-IP, namun untuk sisi administration dapat mengaktifkan fungsi firewal/filtering dan monitoring pada interface EoIP [2].

Penelitian Syariful Ikhwan, Ahya Amalina melakukan analisa perancangan jaringan VPN pada Dinhubkominfo Kabupaten Banyumas. Dengan memanfaatkan teknologi VPN sebagai sistem keamanan jaringan dan membangun tunnel antara kedua kantor, beberapa tunneling yang digunakan diantaranya Point to Point Tunneling Protocol (PPTP) dan Layer Two Tunneling Protocol (L2TP). Berdasarkan dari penelitian ini difocuskan pada pertukaran layanan FTP, dimana parameter QoS yang digunakan yaitu jitter, throughput, delay dan packet loss dengan memberi beban trafik yaitu $512 \mathrm{kbps}, 1024 \mathrm{kbps}$, dan $2048 \mathrm{kbps}$. Hasil yang diperoleh peneliti bahwa rata-rata nilai delay pada L2TP lebih banyak sampai 41\% dibandingkan saat menggunakan PPTP, dengan rata-rata throughput PPTP naik sampai 34\% dibandingkan dengan L2TP, dan rata-rata jitter pada PPTP lebih besar sampai 44\% dibanding dengan L2TP, namun packet loss yang terjadi pada masing-masing layanan adalah 0 [3]. 


\section{A. Virtual Private Network (VPN)}

Virtual Private Network (VPN) adalah sebuah teknologi jaringan komputer yang dikembangkan oleh perusahaan skala besar yang menghubungkan antar jaringan diatas jaringan lain menggunakan internet yang membutuhkan jalur privacy dalam komunikasinya [4].

\section{B. Protokol Routing}

Routing merupakan proses penentuan jalur terbaik sebuah data dalam suatu jaringan. jenis routing memiliki 2 jenis, yaitu : static routing dan dynamic routing. protocol routing dapat diartikan aturan router yang saling berkomunikasi [5].

\section{Tunneling}

Teknologi tunneling merupakan teknologi yang bertugas untuk manangani dan menyediakan koneksi point-to-point dari sumber ke tujuannya. Disebut tunnel (terowongan) karena koneksi point-topoint tersebut sebenarnya terbentuk dengan melintasi jaringan umum, namun koneksi tersebut tidak mempedulikan paketpaket data milik orang lain yang sama-sama melintasi jaringan umum tersebut, tetapi koneksi tersebut hanya melayani transportasi data dari pembuatnya. Hal ini sama dengan penggunaan jalur busway yang pada dasarnya menggunakan jalan raya, tetapi dia membuat jalur sendiri untuk dapat dilalui bus khusus. Koneksi point-to-point ini sesungguhnya tidak benar-benar ada, namun data yang dihantarkannya terlihat seperti benar-benar melewati koneksi pribadi yang bersifat point-to-point[8].

\section{Bridge}

Bridge merupakan suatu alat jaringan yang menyambungkan kedua jaringannya di lapisan sambungan data (data link layer). Bridge ini tidak me-route paketnya pada lapisan jaringan (network layer). Hanya saja secara sederhana mengulangkan paket antara dua jaringan di sambungan lokal (link-local). Bridge ini pun juga merupakan metode koneksifitas yang menggabungkan dua atau lebihnya interface bertipe ethernet atau sejenisnya, berada didalam segmen network yang sama. Suatu proses Bridging berada pada layer data link.

\section{RESEARCH METHOD}

Pada bagian ketiga ini membahas proses perancangan dan implementasi PPTP dan L2TP menggunakan winbox sebagai tools remote dan dibangun menggunakan router mikrotik. layanan yang diimplementasikan adalah file sharing untuk menguji kinerja QoS terdapat berbagai skenario dengan menggunakan wireshark. Gambar 1 terdapat alur penelitian dalam bentuk diagram alur. 


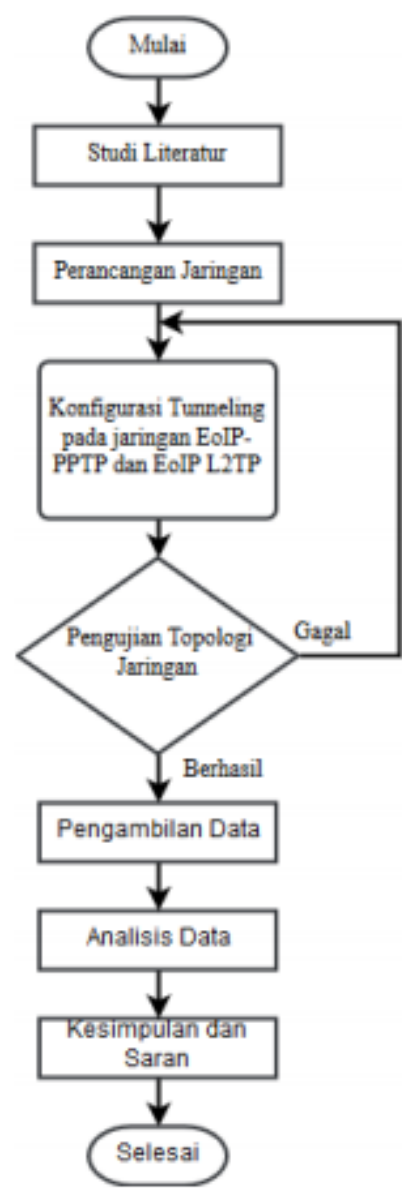

Gambar 1 Alur Penelitian

\section{A. PERANCANANGAN TOPOLOGI JARINGAN}

Topologi jaringan yang digunakan dalam penelitian ini ditunjukan pada Gambar 2, mulai dari perancangan hingga implementasi serta pengolahan dan pengambilan data untuk mengetahui performansi dari fitur tunneling yang di buat untuk proses mengenai alur jaringan, baik disisi konfigurasi router, server, dan client dalam membentuk suatu jaringan EoIP Tunnel dengan memanfaatkan PPTP dan L2TP Tunnel sebagai sistem keamanan pada jaringan lokal. Hal yang perlu diketahui serta dilakukan selanjutnya dengan melakukan bridge EoIP dengan PPTP dan L2TP server/client untuk menggabungkan beberapa interface menjadi satu dengan menggunakan software winbox.exe. Dalam proses perancangan dan implementasi ini lebih mudah di lakukan jika disusun pada alur perencanaan yang baik. Adapun alur dalam perencanaan secara umum dilakukanlah instalasi mikrotik router dilanjutkan dengan konfigurasi sistem antar router dengan konfigurasi Bridge EoIP-PPTP dan L2TP.

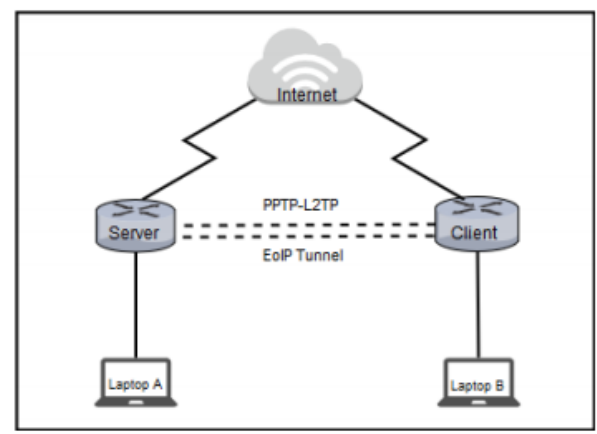

Gambar 2. Topologi Jaringan 
Topologi jaringan tersebut menggunakan dua perangkat router mikrotik, dua laptop dan satu buah smartphone sebagai jaringan wlan alat atau media transmisi data informasi maupun data transfer dari satu laptop ke laptop lain dengan menggunakan metode tunnelling yang berada di antara server dan client.

\section{B. PENGALAMATAN IP}

Setelah topologi jaringan dirancang, kemudian dilanjutkan konfigurasi pengalamatan IP Address beserta interface yang sudah disiapkan dalam suatu jaringan, seperti pada tabel dibawah yang telah disajikan.

Tabel 1. Pengalamatan IP Address

\begin{tabular}{|c|c|c|c|c|}
\hline Perangkat & Jenis IP & Interfaces & Alamat IP & Gateway \\
\hline Laptop Server & \multirow{4}{*}{ IPv4 } & & $192.168 .1 .253 / 24$ & $192,168.1 .1$ \\
\hline Laptop Client & & & $192.168 .1 .251 / 24$ & 192.168 .1 .1 \\
\hline Mikrotik Server & & Ether 2 & $192.168 .1 .254 / 24$ & 192.168 .1 .254 \\
\hline Mikrotik Client & & Ether 2 & $192.168 .1 .252 / 24$ & 192.168 .1 .252 \\
\hline
\end{tabular}

\section{KONFIGURASI JARINGAN}

Membangun jaringan VPN dengan mikrotik sebagai server dan client. Adapun termasuk mode yang dapat digunakan untuk membuat sebuah jaringan VPN dalam penelitian yaitu PPTP dan L2TP. Dengan terbentuknya VPN diharuskan menggunakan protokol tunnel yang sudah support oleh perangkat yang digunakan. Untuk menjadikan PPTP server maupun L2TP server baik secara lokal ataupun publik harus bisa di hubungi atau dipanggil dari sisi client.

\section{VARIASI FILE SHARING}

Penelitian ini menggunakan pengiriman data yang berbeda, untuk data yang diijinkan pada layanan file sharing yaitu rar, pada proses pengambilan data akan digunakan sesuai dengan apa yang diimplementasikan pada router mikrotik dan winbox. Nilai parameter yang akan digunakan yaitu troughput, delay, dan packet loss. Konsep dari penelitian ini menganalisa QoS pada layanan file sharing.

\section{E. PARAMETER QOS}

Quality of Service (Qos) Merupakan metode pengukuran tentang seberapa baik jaringan dan merupakan suatu usaha untuk mendefinisikan karakter dan sifat dari suatu service. QoS digunakan untuk mengukur beberapa atribut kinerja yang telah dispesifikasikan dengan suatu service [6].

\section{THROUGHPUT}

Throughtput adalah nilai rata - rata pengsiriman yang sukses melalui saluran telekomunikasi dalam suatu pengiriman. Throughtput diukur dalam satuan bit per second (bps atau bit/s). Rumus menghitung throughtput ditunjukkan pada persamaan 3.1 [4]

$$
\text { Throughtput }(\text { bps })=\frac{\text { Packet Data yang diterima }(\text { bit })}{\text { Waktu Pengiriman Packet }(\text { second })}
$$

\section{DELAY}

Delay adalah permasalahan umum yang terjadi pada jaringan telekomunikasi. Delay merupakan waktu yang diperlukan sebuah paket untuk melakukan perjalanan dari pengiriman ke penerima. Rumus untuk menghitung delay ditunjukkan pada persamaan 3.2 [4].

$$
\text { Delay Rata }- \text { Rata }=\frac{\text { Total Delay }}{\text { Total Paket yang diterima }}
$$

Klasifikasi standarisasi delay berdasarkan [7] ditunjukkan pada Tabel 2. 
Tabel 2 Klasifikasi standarisasi delay

\begin{tabular}{|c|l|l|}
\hline No & \multicolumn{1}{|c|}{ Kategori } & \multicolumn{1}{c|}{ Besar $(\mathbf{m s})$} \\
\hline 1 & Sangat Baik & $<150$ \\
\hline 2 & Baik & $150-300$ \\
\hline 3 & Cukup Baik & $300-450$ \\
\hline 4 & Tidak Direkomendasikan & $>450$ \\
\hline
\end{tabular}

\section{PACKET LOSS}

Packet loss merupakan parameter yang menggambarkan kondisi yang menunjukkan jumlah paket yang hilang. Rumus untuk menghitung packet loss ditunjukkan pada persamaan 3 [4]

$$
\text { Packet Loss }=\frac{(\text { Paket data dikirim-paket data diterima) } \times 100 \%}{\text { paket data yang dikirim }} \text { (3.3) }
$$

Klasifikasi standarisasi packet loss berdasarkan [7] ditunjukkan pada Tabel 3.

Tabel 3. Klasifikasi standarisasi packet loss

\begin{tabular}{|c|l|l|}
\hline No & \multicolumn{1}{|c|}{ Kategori } & \multicolumn{1}{|c|}{ Besar (\%) } \\
\hline 1 & Sangat Baik & $0-2$ \\
\hline 2 & Baik & $3-14$ \\
\hline 3 & Cukup Baik & $15-25$ \\
\hline 4 & Tidak Direkomendasikan & $>25$ \\
\hline
\end{tabular}

\section{RESUlTS AND DiscuSSION}

Pada hasil pengujian penelitian yang telah dilakukan dengan analisa performansi metode tunnelling PPTP dan L2TP pada mikrotik dengan layanan Sharing Data yang didapatkan informasi Quality of Service (QoS).Parameter QoS yang didapatkan seperti troughtput, delay, packet loss pada saat melakukan sharing data dari server ke client. Parameter tersebut didapatkan berdasarkan aktifitas nilai trafik aliran paket data pada software wireshark yang berfungsi sebagai analisa jaringan yang dipasang di client dan server.

\section{A. THROUGHPUT}

Berikut ini yang berisi informasi hasil pengambilan data parameter throughput yang diperoleh berdasarkan pengujian layanan file sharing dalam beberapa variasi ukuran data ditampilkan pada tabel 4 .

Tabel 4. Troughput layanan file transfer

\begin{tabular}{|c|c|c|}
\hline \multicolumn{3}{|c|}{ TROUGHTPUT (Mbps) } \\
\hline UKURAN DATA & PPTP & L2TP \\
\hline 5Mbps & 6.3315 & 6.2163 \\
\hline $10 \mathrm{Mbps}$ & 6.5363 & 6.5616 \\
\hline $15 \mathrm{Mbps}$ & 4.5677 & 6.6096 \\
\hline
\end{tabular}

Pada penelitian ini, dari setiap variasi data pada skenario yang dilakukan menentukan hasil dari nilai data parameternya. Semakin kecil ukuran data yang digunakannya tentu saja semakin naik nilai troughput. Throughput itu pun merupakan besaran paket atau jumlah bit dari sebuah data atau file yang diterima oleh client atau penerima. Pada nilai throughput L2TP itu sendiri lebih besar yang didapatkannya setiap variasi data yaitu 6.2169, 6.5616, dan 6.6096 Mbps, dibandingkan dengan throughput PPTP yang didapatkan lebih kecil untuk setiap pengujian nilai paket datanya variasi yaitu 6.3315, 6.5363, dan 4.5677 Mbps. Hal ini mempengaruhi kinerja dari parameter seperti delay dan packet loss. 


\section{B. DELAY}

Nilai delay setiap paket data yang didapatkan kemudian diolah menjadi total rata-rata delay di setiap skenario. Hasil tersebut yang didapat dilakukanlah perbandingan sesuai dengan standarisasi TIPHON TS 101 329-2. Berikut Tabel 5 data informasi mengenai total rata-rata delay disetiap skenario pengujian.

Tabel 5. Delay layanan file transfe

\begin{tabular}{|c|c|c|}
\hline \multicolumn{3}{|c|}{ DELAY (ms) } \\
\hline UKURAN DATA & PPTP & L2TP \\
\hline 5Mbps & 0.9074 & 0.9753 \\
\hline 10Mbps & 0.8802 & 0.8903 \\
\hline 15Mbps & 2.5452 & 0.8793 \\
\hline
\end{tabular}

Nilai ukuran data tersebut juga berpengaruh terhadap kecepatan transfer paket data pada saat file sharing yang berjalan dari sisi server ke sisi client. Hal ini dapat membuktikan untuk protokol PPTP semakin besar ukuran data bahwa lebih besar nilai delay yang didapat pada variasi $15 \mathrm{Mb}$ dibandingkan dengan variasi data 5 dan $10 \mathrm{Mb}$ delay yang didapatkan kecil. Sedangkan protokol L2TP semakin rendah ukuran data bahwa lebih besar delay yang didapat pada variasi $5 \mathrm{Mb}$ dibandingkan dengan variasi data 10 dan $15 \mathrm{Mb}$ delay yang didapat kecil. Semakin rendah nilai ukuran data maka nilai delay akan semakin besar, dan semakin besar nilai ukuran data maka delay pun semakin kecil.

\section{PACKET LOSS}

Jaringan dengan antrian pengiriman paket data yang besar akan memiliki nilai packet loss yang besar, begitupun sebaliknya. Selain itu, kegagalan link transmisi dan kapasitas yang tidak mencukupi merupakan beberapa faktor yang mengakibatkan terjadinya packet loss Berikut tabel data informasi mengenai total rata-rata delay disetiap skenario.

Tabel 6. Delay layanan file transfer

\begin{tabular}{|c|c|c|}
\hline \multicolumn{3}{|c|}{ PACKET LOSS (\%) } \\
\hline UKURAN DATA & PPTP & L2TP \\
\hline 5Mbps & 0 & 0 \\
\hline $10 \mathrm{Mbps}$ & 0 & 0,0025 \\
\hline $15 \mathrm{Mbps}$ & 176,802 & 0,0039 \\
\hline
\end{tabular}

Hal ini terjadi dikarenakan masing-masing protokol tidak melakukan pengulangan pengiriman paket yang hilang. Selain itu juga, adanya kesibukan yang terjadi pada jaringan yang tidak stabil terkadang bagus dan tidak. Namun nilai dari packet loss antara PPTP dengan L2TP masih masuk kategori standarisasi packet loss dari TIPHON TR 101 329, namun jika dibandingkan PPTP dengan L2TP nilai packet loss yang sangat baik adalah L2TP dikarenakan masih dalam kategori nilai rentang 0-1\%.

\section{CONCLUSION}

Kesimpulan dari penelitian Performasi EOIP-PPTP dengan EOIP-L2TP pada router Mikrotik ialah protokol L2TP lebih baik di sisi throughput dan nilai paket loss lebih kecil daripada protokol PPTP. Hasil untuk pengukuran nilai delay, delay itu merupakan waktu tunda yang ditempuh suatu paket tersebut sampai paket tersebut diterima, maka nilai pada delay sangat dipengaruhi oleh besar atau kecilnya ukuran data. semakin ukuran data besar maka delay yang diperoleh kecil dan sebaliknya jika ukuran file data semakin kecil maka delay besar. Nilai ukuran data tersebut juga berpengaruh terhadap kecepatan transfer paket data pada saat file sharing yang berjalan dari sisi server ke sisi client

\section{ACKNOWLEDGMENT}


Penulis ingin mengucapkan kepada semua pihak yang membantu penelitian penulis, baik itu tenaga pengajar dan tenaga staff yang sudah mendukung penelitian penulis.

\section{REFERENCES}

[1] D. Cahyadi, "Pemanfaatan Fitur Tunneling Menggunakan Virtual Interface EoIP di MikrotikRouterOS Untuk Koneksi Bridging Antar Kantor Melalui Jaringan ADSL Telkom Speedy,” J. Inform. Mulawarman, vol. 5, no. Fitur Tunnling, pp. 50-54, 2010.

[2] H. Kuswanto and T. Informatika, "Implementasi Jaringan Virtual Private Network ( VPN ) Menggunakan Protokol EoIP," vol. 19, no. 1. pp. 46-51, 2017.

[3] S. Kasus and D. Kabupaten, “Analisis Jaringan VPN Menggunakan PPTP dan L2TP,” vol. 9, no. 3, pp. 265-270, 2017.t

[4] B. A. Forouzan, Data Communications and Networking, Fourth Editi, 4th ed. 2007.

[5] S. S. STMIK AKBA, "Konsep Routing," Jaringan Komputer, p. 1.

[6] "Internetworking Technology Handbook," 2005.

[7] "Telecommunications and Internet Protocol Harmonization Over Networks (TIPHON); General aspects of Quality of Service (QoS), Etsi, 1999

[8] O. W. Purbo; "Virtual Private Network (VPN) sebagai alternatif Komunikasi Data Pada Jaringan Skala Luas (WAN)," 2015. 